\title{
Arsenic removal by a membrane hybrid filtration system
}

\author{
V. T. Nguyen, S. Vigneswaran*, H. H. Ngo, H.K. Shon, and J. Kandasamy \\ Faculty of Engineering, University of Technology Sydney (UTS), P.O. Box 123, Broadway, \\ NSW 2007, Australia. \\ *corresponding author, Email: s.vigneswaran@uts.edu.au, Ph +612 9514 2641, Fax +612 \\ 95142633
}

\begin{abstract}
:
Arsenic is a toxic semi-metallic element that can be fatal to human health. Membrane filtration can remove a number of contaminants from water, including arsenic. Removal of arsenic by membrane filtration is highly dependent on the species of arsenic and the properties of the membrane. The performance of the nanofilter is better for removing $\mathrm{As}(\mathrm{V})$ than As(III). About 57\% of As(III) and $81 \%$ of As(V) was removed from $500 \mu \mathrm{g} / \mathrm{L}$ arsenic solutions by nanofiltration (NTR729HF, Nitto Denko Corp., Japan) of 700 molecular weight (MW) cutoff. The removal efficiency of microfiltration (MF) was much lower than that of nanofiltration (NF) due to its larger pore size. By comparison only 37\% of As(III) and $40 \%$ of As(V) were removed by microfiltration (PVA membrane, Pure-Envitech, Korea). However, the removal efficiency of microfiltration was increased dramatically when a small amount of nanoscale zero valent iron (nZVI) was added. The removal efficiency by MF increased up to $90 \%$ with $\mathrm{As}(\mathrm{V})$ and $84 \%$ with As(III) when an amount of $0.1 \mathrm{~g} / \mathrm{L}$ of nZVI was added into the arsenic solution.
\end{abstract}

Keywords: arsenic, nanometer-scale zero valent iron, membrane, drinking water treatment

\section{Introduction}

Water is the essence of life and "Access to safe water is a fundamental human need and, therefore, a basic human right” (Kofi Annan, 2001). In many regions in the world, however, especially in developing countries, millions of people still suffer from the lack of access to safe drinking water. This harms people's health and can cause serious illnesses.

One of the problems in drinking water that raises concern over the world is that millions of people still have to use arsenic contaminated water. Medical research indicates that exposure to arsenic in drinking water causes urinary, bladder, lung and skin cancers, gastrointestinal disorders, muscular weakness, loss of appetite, nerve tissue injuries and blackfoot disease.

The arsenic contamination in water forced the water and health authorities to introduce stringent standards for arsenic levels in drinking water. World Health Organization (WHO) has recommended the arsenic level in drinking water to the stricter level to be $10 \mu \mathrm{g} / \mathrm{L}$ instead of $50 \mu \mathrm{g} / \mathrm{L}$. The U.S. Environmental Protection Agency (EPA) has lowered the maximum contaminant level (MCL) of arsenic from $50 \mu \mathrm{g} / \mathrm{L}$ to $10 \mu \mathrm{g} / \mathrm{L}$.

Arsenic exists in several oxidation states (-III, 0, +III and $+\mathrm{V}$ ) in the environment. However, in natural water, arsenic is mostly found in an inorganic form as oxyanions of trivalent arsenite (As(III)) or pentavalent arsenate (As(V)).

Different treatment technologies such as coagulation, ion exchange, adsorption, and membrane processes are used to remove arsenic from drinking water to produce water of a safe quality.

Appropriate treatment depends on many factors, for example, concentration of arsenic, water composition, $\mathrm{pH}$ and cost effectiveness. In contrast to cyanide, arsenic cannot be destroyed.

Arsenic removal by membrane technology 
When membranes were first evaluated for arsenic removal, cellulose - acetate RO membranes were operated at high pressures (typically 2,758 $\mathrm{kPa}$ ), and more than $90 \%$ arsenate rejection was reported (Schneiter and Middlebrooks, 1983; Clifford 1986).

In the mid-90s, NF membranes, which are more permeable and can be operated at pressures less than $689 \mathrm{kPa}$, were also found effective for arsenic removal (Legault et al., 1993; Waypa et al., 1997). One disadvantage of both RO and NF membranes is that only a small amount of the raw water (10 - 15\%) passes through the membrane as permeate. Multiple membrane units in series are needed to achieve higher recovery rates (80 to over $90 \%$ ).

In recent years, new generations of RO and NF membranes that are less expensive and operate at lower pressures have been developed. Waypa et al. (1997) showed that some of the new membranes, operated at pressures ranging from $276-2,758 \mathrm{kPa}$, are able to reject from 96 - 99\% of both arsenate and arsenite in spiked natural waters. They attributed this rejection of arsenite to the relatively large molecular weight of arsenate and arsenic, rather than charge repulsion. Due to its high arsenic rejection capacity, membrane filtration can produce extremely low arsenic concentrations in treated water. The performance of the NF membrane was comparably good with RO membranes; even though the operating pressure was much lower (276 - $827 \mathrm{kPa}$, compared to 1,379 - 2,758 kPa for RO).

Arsenic removal by adsorption on material contain iron

Zero valent iron: Zero valent iron (ZVI) is an inexpensive and moderately strong reducing agent (Genin et al., 1998). It is used as a catalyst in the chemical synthesis in industrial applications and is capable of removing many common environmental contaminants, such as $\mathrm{Cr}(\mathrm{VI})$, Se, and $\mathrm{NO}_{3}$. Lackovic et al. (2000) showed that zero valent iron filings could be used either in situ or ex situ to remove arsenate, and produce ferrous iron, which eventually precipitates out. Arsenite is removed either through coprecipitation or adsorption onto pyrite. The drawback of zero valent iron is that the treated water contains very high ferrous iron. Therefore, another removal treatment process is needed to remove the ferrous iron.

The arsenic removal mechanism is mainly due to spontaneous adsorption and coprecipitation of arsenic with iron(II) and iron(III) oxides/hydroxides, which form in-situ during ZVI oxidation (corrosion) (Lackovic et al., 2000; Farrell et al., 2001). The oxidation of ZVI by water and oxygen can be presented by the following equations:

$$
\begin{array}{lll}
\mathrm{Fe}^{0}+2 \mathrm{H}_{2} \mathrm{O} & \rightarrow & 2 \mathrm{Fe}^{2+}+\mathrm{H}_{2}+2 \mathrm{OH}^{-} \\
\mathrm{Fe}^{0}+\mathrm{O}_{2}+2 \mathrm{H}_{2} \mathrm{O} & \rightarrow & 2 \mathrm{Fe}^{2+}+4 \mathrm{OH}^{-}
\end{array}
$$

$\mathrm{Fe}(\mathrm{II})$ further reacts to give magnetite $\left(\mathrm{Fe}_{3} \mathrm{O}_{4}\right)$, ferrous hydroxide $\left(\mathrm{Fe}(\mathrm{OH})_{2}\right)$, and ferric hydroxide $\left(\mathrm{Fe}(\mathrm{OH})_{3}\right)$ depending upon redox conditions and $\mathrm{pH}$.

$$
\begin{array}{lll}
6 \mathrm{Fe}^{2+}+\mathrm{O}_{2}+6 \mathrm{H}_{2} \mathrm{O} & \rightarrow & 2 \mathrm{Fe}_{3} \mathrm{O}_{4}(\mathrm{~s})+12 \mathrm{H}^{+} \\
\mathrm{Fe}^{2+}+2 \mathrm{OH}^{-} & \rightarrow & \mathrm{Fe}(\mathrm{OH})_{2}(\mathrm{~s}) \\
6 \mathrm{Fe}(\mathrm{OH})_{2}(\mathrm{~s})+\mathrm{O}_{2} & \rightarrow & 2 \mathrm{Fe}_{3} \mathrm{O}_{4}(\mathrm{~s})+6 \mathrm{H}_{2} \mathrm{O} \\
\mathrm{Fe}_{3} \mathrm{O}_{4}(\mathrm{~s})+\mathrm{O}_{2}(\mathrm{aq})+18 \mathrm{H}_{2} \mathrm{O} & \leftrightarrow & 12 \mathrm{Fe}(\mathrm{OH})_{3}(\mathrm{~s})
\end{array}
$$

Heterogeneous reactions at the corroding ZVI surface are complex and result in a variety of potential adsorption surfaces for As(III) and As(V). Despite this complexity, studies using Xray absorption spectroscopy showed that the products after reaction of As(III) and As(V) with ZVI were innersphere As(III) and As(V) surface complexesoniron(III) oxides/hydroxide corrosion products (Farrell et al., 2001; Manning et al., 2002).

Nanoscale zero valent iron nZVI: The versatility of nanometer-scale zero valent iron (nZVI) material has been demonstrated in many potential applications in environmental engineering. Due to the extremely small particle size, large surface area, and high in-situ reactivity, these materials have great potential in a wide array of environmental applications such as in soil, sediment, and groundwater remediation (Wang and Zhang, 1997; Lien and Zhang, 1999). Kanel et al. (2005) found that the particle sizes of nZVI ranged from 10 to $100 \mathrm{~nm}$. The kinatics of arsenic(III) adsorption onto nZVIwere rapid and occurred in minutes following a 
pseudo first order rate expression with observed reaction rate constants of $0.07-1.3 \mathrm{~min}^{-1}$, about 1,000 times higher than that of micron size ZVI.

Due to the extremely small particle size, large surface area, and high in-situ reactivity, the combination of nanoscale zero valent iron with membrane is believed to lead to very high treatment efficiency, but no studies have reported the efficacy of a hybrid system of micro/nanofiltration with in line addition of nZVI on arsenic removal. In this study, experiments were performed using a microfiltration (MF) and nanofiltration (NF) alone and in combination with in - line nanoscale zero valent iron addition to investigate the effectiveness of a new hybrid membrane system in removing arsenic.

\section{Materials and methods}

In this study, synthetic water was used. Synthetic water was prepared by adding arsenic stock solution $(1 \mathrm{~g} / \mathrm{L})$ in distilled water to obtain predetermined concentration of arsenic $(500 \mu \mathrm{g} / \mathrm{L})$. The experiments were conducted at different $\mathrm{pH}$ values from 5 to 9. Solutions $1 \mathrm{M} \mathrm{HNO}_{3}$ and $\mathrm{NaOH}$ were used to adjust the $\mathrm{pH}$.

All chemicals used in the studies were reagent grade, and used without any purification.

Arsenite [As(III)] stock solution $(1,000 \mathrm{mg} / \mathrm{L})$ and arsenate [As(V)] were prepared by dissolving $1.3223 \mathrm{~g}$ of oxide arsenite $\left(\mathrm{As}_{2} \mathrm{O}_{3}\right.$, Ajax Chemical) $4.164 \mathrm{~g}$ of sodium arsenate $\left(\mathrm{Na}_{2} \mathrm{HAs}_{4} .7 \mathrm{H}_{2} \mathrm{O}\right.$, Sigma - Aldrich) into $1 \mathrm{~L}$ distilled water respectivelly.

Nanoscale zero valent iron was prepared as per Sherman et al. (2000). $10.00 \mathrm{~g}$ of $\mathrm{FeSO}_{4} \cdot 7 \mathrm{H}_{2} \mathrm{O}$ was dissolved in $100 \mathrm{~mL}$ of $30 \%$ technical grade ethanol, and $70 \%$ deionized water $(\mathrm{v} / \mathrm{v})$ under non oxygen environment. The $\mathrm{pH}$ was adjusted to about 6.8 with $3.8 \mathrm{M} \mathrm{NaOH}$. $\mathrm{NaBH}_{4}$ powder (1.8 g) was added incrementally to the mixture, allowing the foaming to subside between increments. After addition of all of the $\mathrm{NaBH}_{4}$, the mixture was stirred for 20 minutes. The solid was washed twice with technical grade ethanol, effectively substituting ethanol for the water in the mixture. This step helps to prevent immediate rusting as the filtration process is completed.

The membranes used in this study were NTR 729HF polyvinyl alcohol/polyamid NF (Nitto Denko Corp., Japan) and Poly Vinyl Alcohol MF (PVA, MF, Pure-Envitech, Korea). These membranes were used in the (i) nanofilter and microfilter and (ii) nanofilter - nanoscale zero valent iron and microfilter - nanoscale zero valent iron hybrid systems to study the effectiveness of these processes in arsenic removal. Both membranes used in this study were made from polymer. The detailed characteristics of this membrane are presented from Tables 1 and 2. Figure 1 presents the SEM image of these membranes.

Table 1. Specification of NTR729HF membrane obtained from the manufacturer (Nitto Denko Corp., Japan)

\begin{tabular}{|c|c|c|}
\hline \multicolumn{2}{|r|}{ Membrane } & NTR 729HF \\
\hline \multicolumn{2}{|c|}{$\mathrm{NaCl}$ rejection } & 92 \\
\hline \multirow{5}{*}{ 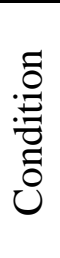 } & Concentration (\%) & 0.15 \\
\hline & Pressure $(\mathrm{MPa})$ & 1.0 \\
\hline & Temperatute $\left({ }^{\circ} \mathrm{C}\right)$ & 25 \\
\hline & Recovery (\%) & $10-20$ \\
\hline & $\mathrm{pH}$ & 6.5 \\
\hline \multirow{4}{*}{$\begin{array}{l}\ddot{\infty} \\
\text { ే } \\
\widetilde{\simeq}\end{array}$} & Maximum temperature & 40 \\
\hline & $\mathrm{pH}$ & $2-8$ \\
\hline & Maximum pressure & 2.9 \\
\hline & Chlorine (mg/L) & $<1$ \\
\hline
\end{tabular}


Table 2. Specification of PVA membrane obtained from the manufacturer (Pure-Envitech, Korea)

\begin{tabular}{|l|c|}
\hline \multicolumn{1}{|c|}{ Membrane } & MF \\
\hline Material & Poly vinylidene fluoride \\
\hline Pore size $(\mu \mathrm{m})$ & 0.4 \\
\hline Contact angle $\left(^{\circ}\right)$ & 94 \\
\hline Pure water permeability $\left(\mathrm{L} / \mathrm{m}^{2} . \mathrm{h}\right)$ at $30 \mathrm{kPa}$ & 3300 \\
\hline
\end{tabular}

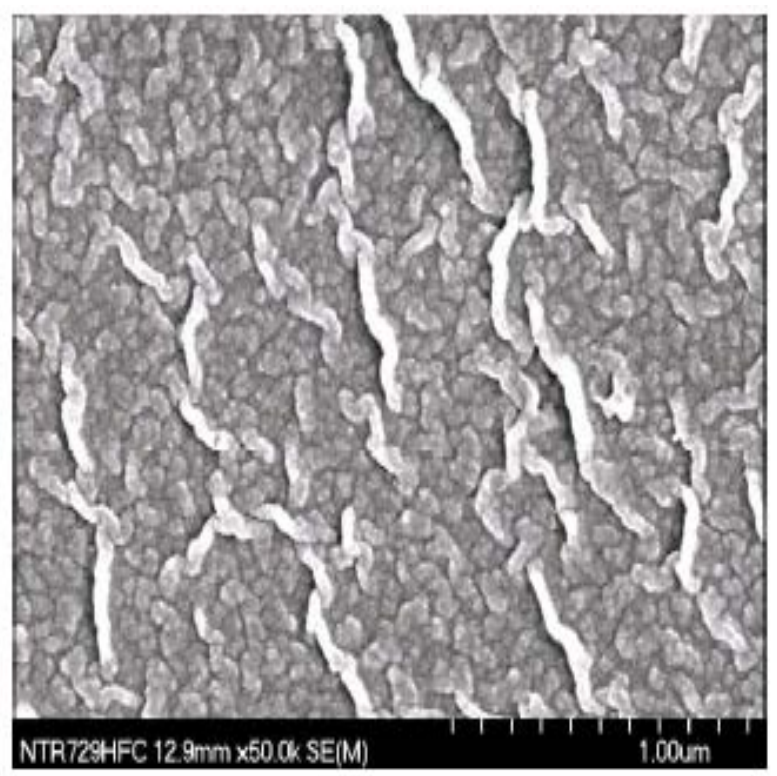

(a) NTR 729HF

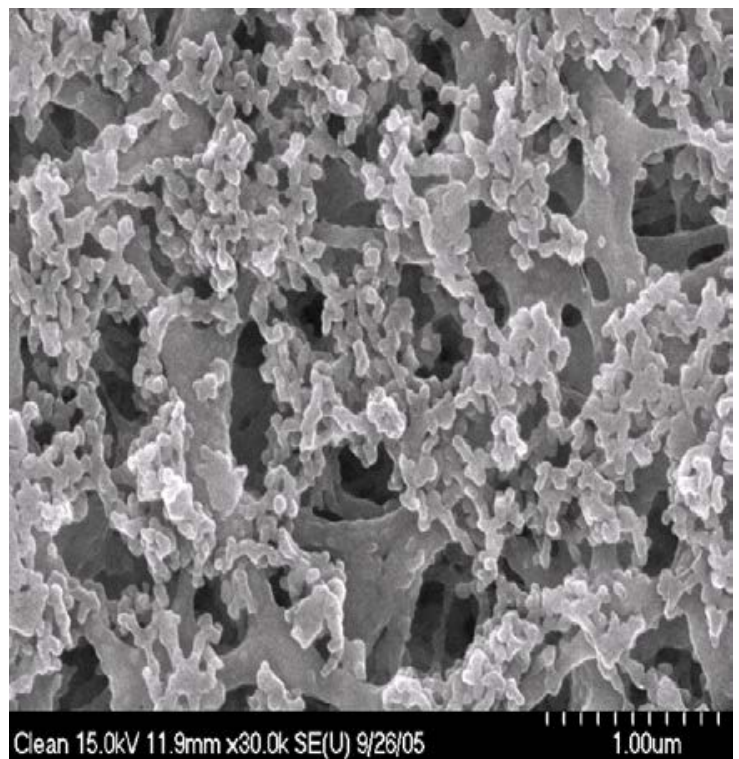

(b) PVA

Figure 1. SEM images of membranes

The membrane filtration experimental set-up is shown in Figure 2. The cross - flow membrane unit (Nitto Denko Corp.) was used to study the effect of different membranes on arsenic removal with and without in line addition of nZVI. The synthetic water (with an arsenic concentration of $500 \mu \mathrm{g} / \mathrm{L}$ ) was pumped to a flat sheet membrane module with an effective membrane area of $0.006 \mathrm{~m}^{2}$. The operating pressure and cross - flow velocity were controlled at 10 - $500 \mathrm{kPa}$ by means of by-pass and regulating valves. New membranes were used in each experiment to avoid the effect of residual nZVI on membrane filtration and to compare the results obtained under different membrane operating conditions.

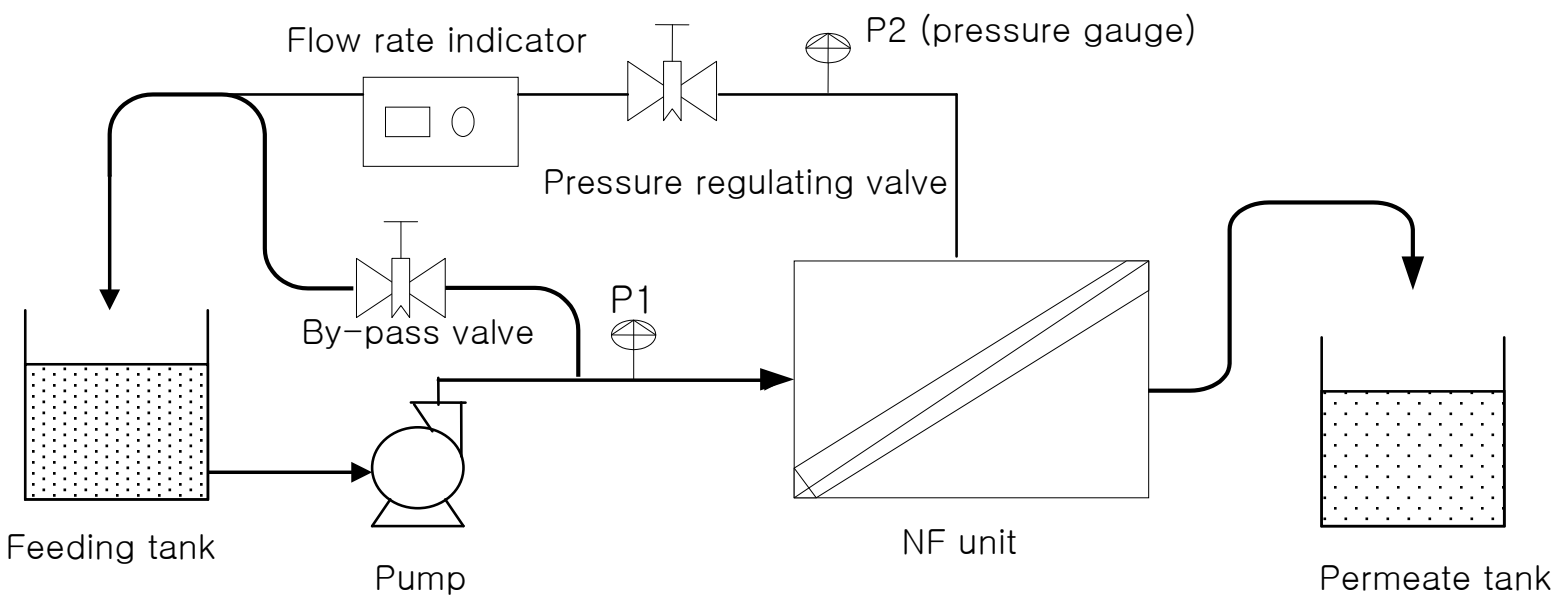

Figure 2. Schematic of the cross-flow unit 
All samples were acidified with $0.3 \% \mathrm{HNO}_{3}$ (trace metal grade), and analysed for arsenic using a hydride generation atomic absorption spectrometry (HGAAS), model AAS 932 Plus and HGGBC 3000.

\section{Results and discussion}

\section{III.1. Effect of applied pressure on the membrane filtration}

As a first step, arsenic removal by nanofiltration was studied.

Figure 3 presents the removal efficiency of arsenic by membrane filtration at different operating pressures. As can be seen from Figure 3, arsenic removal efficiency increased slightly with the increase in transmembrane pressure (TMP). The permeate flux increased as the pressure increased, which resulted in lower arsenic concentration in the permeate water. Removal efficiency of $\mathrm{As}(\mathrm{V})$ was significantly higher than that of $\mathrm{As}(\mathrm{III})$ within the investigated pressure range of 85 to $500 \mathrm{Kpa}$. For all the six pressure values studied, $\mathrm{As}(\mathrm{V})$ removal efficiency was above $80 \%$ while As(III) removal was less (which ranged from 54 $59 \%)$. The reason for the difference may be that As(III) is present in a neutral molecular form while $\mathrm{As}(\mathrm{V})$ exists in a negatively monovalent form.

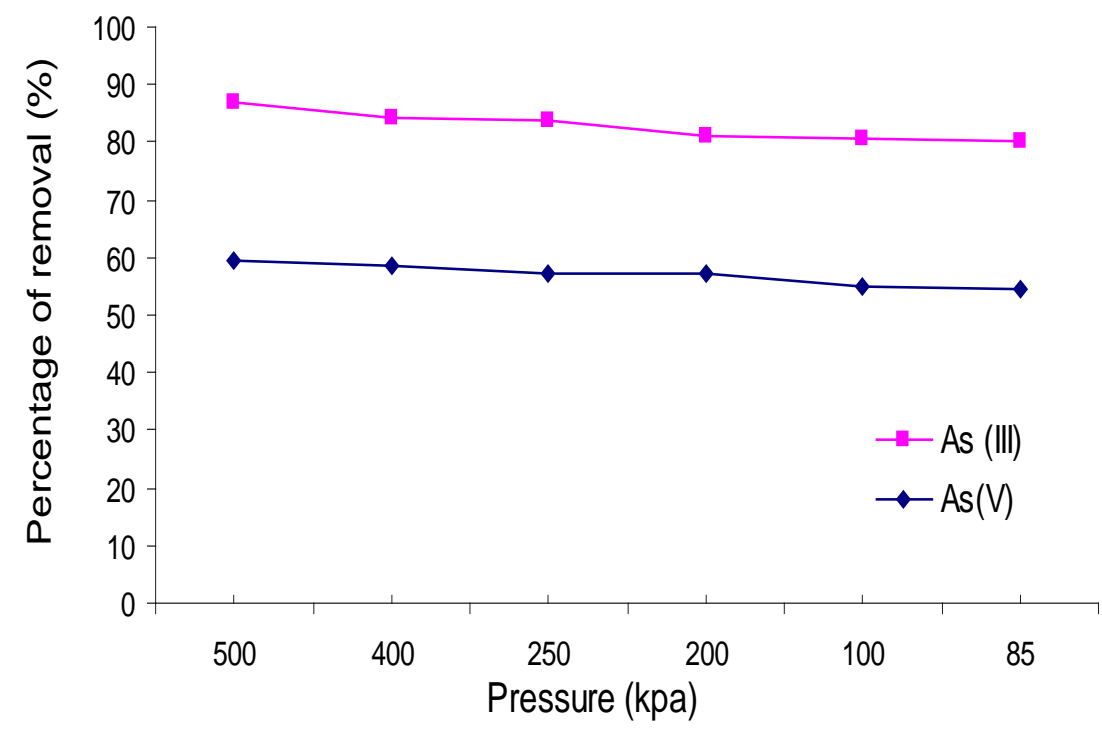

Figure 3. Effect of pressure on arsenic removal by NF

(Nanofilter used was NTR729HF, Initial arsenic concentration $=500 \mu \mathrm{g} / \mathrm{L}$,

Samples were collected after 2 hours of operation)

\section{III.2. Effect of nanoscale zero valent iron}

Figures 4 and 5 present the removal efficiency of As(III) and As(V) (initial concentration of $500 \mu \mathrm{g} / \mathrm{L}$ ) by microfiltration (MF) and nanofiltration (NF) respectively.

As can be seen from Figure 4, the removal efficiency of MF alone was low (about 37\% with As(III) and 40\% with As(V)). The removal efficiency increased dramatically when nanoscale zero valent iron (nZVI) was added into the solution. The removal efficiency of As(V) was slightly higher than that of As(III). The efficiency reached to 90\% with As(V) and 84\% with As(III) when a even small amount of nZVI of $0.1 \mathrm{~g} / \mathrm{L}$ was added in arsenic solution. 


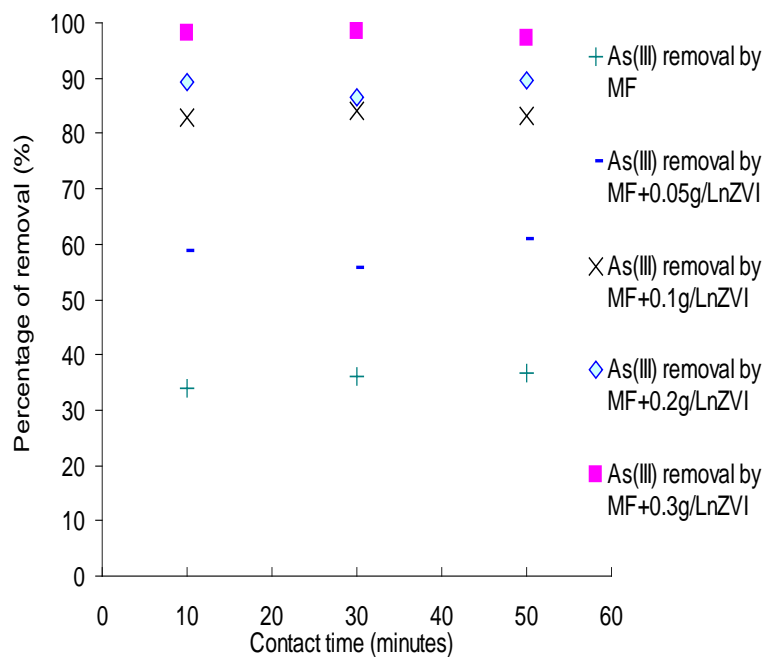

(a). As(III)

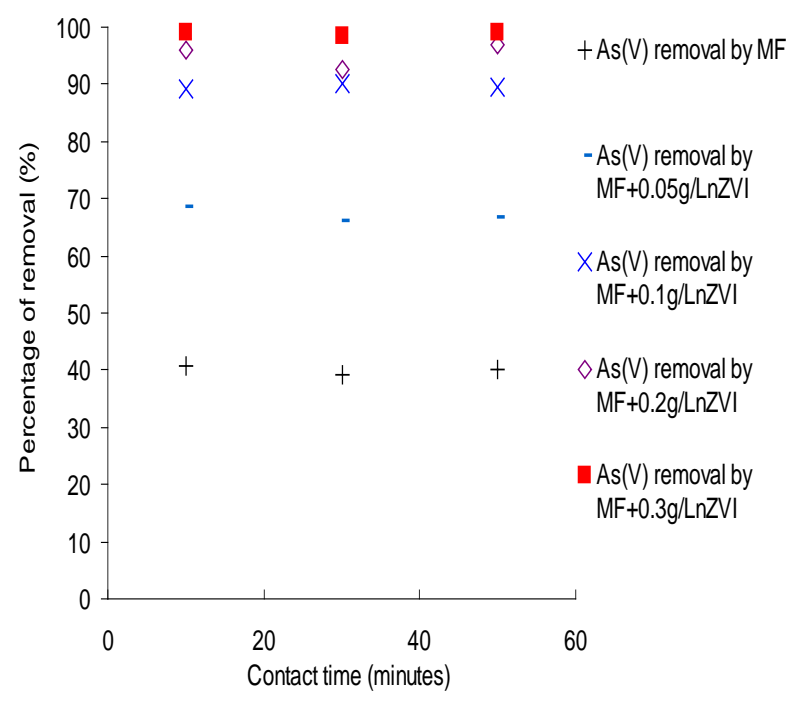

(b). $\mathrm{As}(\mathrm{V})$

Figure 4. Arsenic removal efficiency by microfiltration (MF)

(Microfilter used was PVA, Initial As(III) and As(V) concentration $=500 \mu \mathrm{g} / \mathrm{L}$, Pressure $=10 \mathrm{Kpa})$

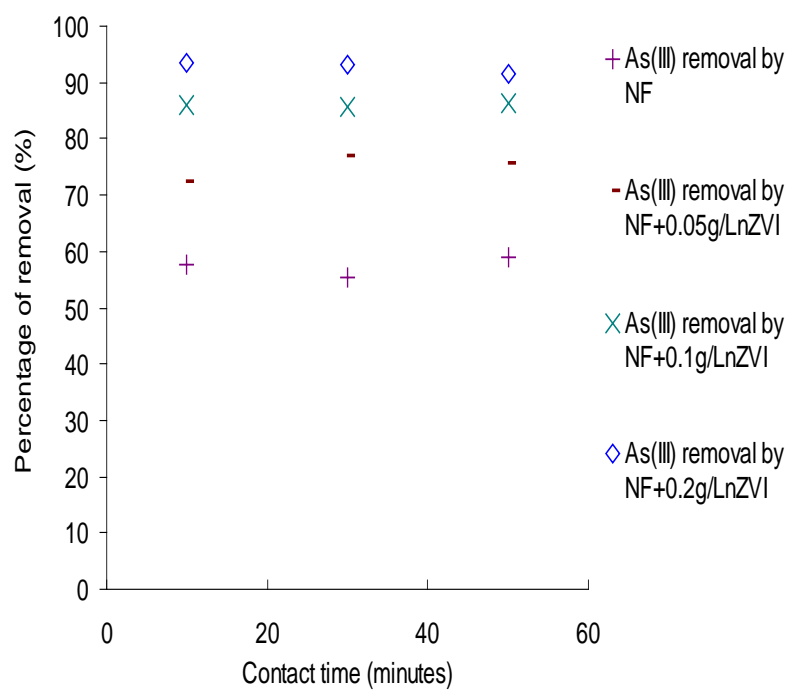

(a). As(III)

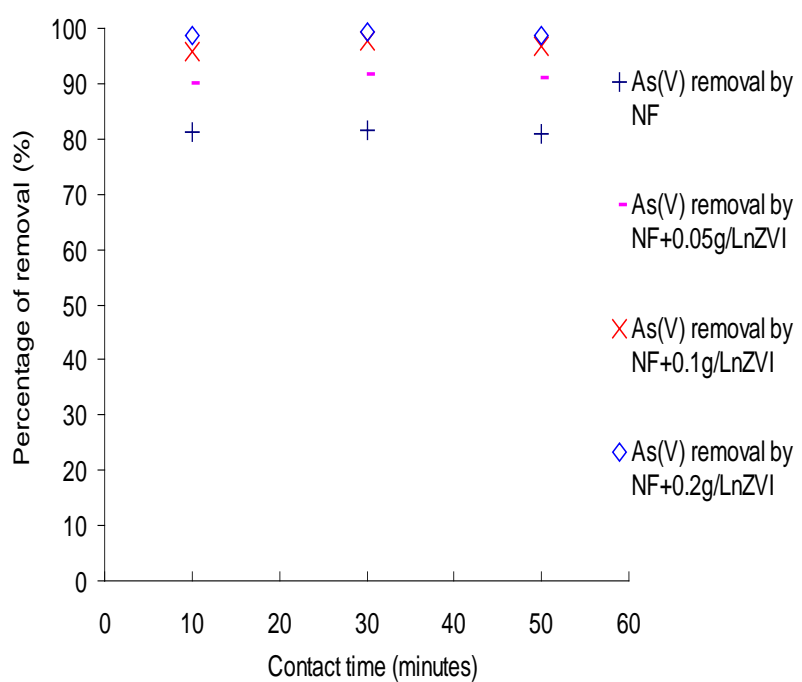

(b). $\mathrm{As}(\mathrm{V})$

Figure 5. Arsenic removal efficiency by nanofiltration (NF)

(Reaction conditions: Initial As(III) and As(V) concentration $=500 \mu \mathrm{g} / \mathrm{L}$, pressure $=200 \mathrm{Kpa}$, Nanofilter used was NTR729HF)

The use of NF improved the arsenic removal efficiency considerably compared to MF alone. $\mathrm{NF}$ alone could remove up to $81 \%$ of $\mathrm{As}(\mathrm{V})$ and $57 \%$ of $\mathrm{As}(\mathrm{III})$. The removal efficiency increased to $97 \%$ with $\mathrm{As}(\mathrm{V})$ and $86 \%$ with $\mathrm{As}(\mathrm{III})$ when $0.1 \mathrm{~g} / \mathrm{L}$ of nZVI was added in the solution (Figure 5).

The success of the combination of nZVI and membrane process in the separation of arsenic in water can be attributed to the high arsenic adsorption onto nZVI prior to their separation by 
membranes. The increase in removal is also attributed to the distribution of nZVI on the membrane surface. Thus, it reduces the transport of arsenic through the membrane.

The first advantage of the MF-nZVI hybrid system in comparison with conventional NF system is that the former requires much lower energy as it can operate under low pressure (10 $\mathrm{Kpa}$ ). As a result, it helps reduce the energy operating cost. Secondly, the MF-nZVI hybrid system can yield a higher amount of treated water.

The following table summaries the removal efficiency of hybrid systems of MF - nZVI in comparison with NF.

Table 3. Comparison of removal efficiency of hybrid system MF-nZVI with NF

(Nanofilter used was NTR729HF, microfilter used was PVA, arsenic concentration $=500 \mu \mathrm{g} / \mathrm{L}$ )

\begin{tabular}{|c|c|c|c|}
\hline \multirow{2}{*}{$\begin{array}{c}\text { Membrane } \\
\text { type }\end{array}$} & $\begin{array}{c}\text { nZVI adding } \\
\text { (g/L) }\end{array}$ & As(III) & Rs (V) \\
\cline { 3 - 4 } NF & 0 & 57 & 81 \\
\hline \multirow{3}{*}{ MF } & 0 & 37 & 40 \\
\cline { 2 - 4 } & 0.05 & 58 & 67 \\
\cline { 2 - 4 } & 0.1 & 84 & 90 \\
\cline { 2 - 4 } & 0.2 & 88 & 95 \\
\cline { 2 - 4 } & 0.3 & 98 & 99 \\
\hline
\end{tabular}

The significant improvements of arsenic removal efficiency (16 - 50\%) were observed by nZVI - NF and nZVI - MF hybrid systems in comparison with NF and MF systems.

\section{Conclusions}

In this study, a new hybrid membrane system which includes an in-line addition of of nanoscale zero valent iron with membrane processes in removing arsenic was investigated for its capacity in removing arsenic from water in detail. The results show that properties of membranes and species of arsenic affect the arsenic removal efficiency by membrane filtration. Nanofilter (NTR729HF, 700 molecular weight cutoff) could remove 57\% of As(III) and $81 \%$ of $\mathrm{As}(\mathrm{V})$ from $500 \mu \mathrm{g} / \mathrm{L}$ arsenic solution whereas the microfilter (PVA, pore size of $0.4 \mu \mathrm{m}$ ) removed only $37 \%$ of $\mathrm{As}(\mathrm{III})$ and $40 \%$ of $\mathrm{As}(\mathrm{V})$. Both microfiltration (MF) and nanofiltration (NF) could remove the majority of the arsenic (more than 90\%) when a small amount of nZVI was added in the water. This hybrid process of nZVI - MF or nZVI - NF resulted in permeates with arsenic concentrations of below $10 \mu \mathrm{g} / \mathrm{L}$ from water containing $500 \mu \mathrm{g} / \mathrm{L}$. This meets the current standard of WHO. This method is feasible when high quality effluent is necessary.

\section{Ackowledgements}

This research was funded by Australian Research Council (ARC) Discovery Grant (20042006) and ARC International Linkage Grant (2003-2004).

\section{References}

D. Clifford, Environ. Sci. Tech. 20 (1986) 1072-1080.

J. Farrell, J. Wang, P. O’Day, M. Coklin, Environ. Sci. Tech. 35 (2001) 2026-2032.

J. M. Genin, G. Bourrie, F. Trolard, M. Abdelmoula, A. Jaffrezic, P. Refait, V. Maitre, B. Humbert, A. Herbillon. Environ. Sci. Tech. 32 (1998) 1058-1068.

S.R. Kanel, B. Manning, L. Charlet, H. Choi. Environ. Sc. Tech. 39 (2005) 1291-1298.

J. A. Lackovic, N. P. Nikolaids, G. M. Dobbs. Environ. Eng. Sci. 17 (2000) 29-39.

A. S. Legault, K. Volchek, A. Y. Tremblay, H. Whittaker. Environ. Pro. 12 (1993) 157-159. 
H. L. Lien, W. Zhang. J. Environ. Eng. 125 (1999) 1042-1047.

B. A. Manning, M. Hunt, C. Amrhein, J. A. Yarmoff. Environ. Sci. Tech. 36 (2002) 54555461.

R.W. Schneiter, E.J. Middlebrooks. Environ. Inter. 9 (1983) 289-291.

M. P. Sherman, G. D. John, E. M. Thomas. Environ. Sc. Tech.; 34 (2000) 2564 -2569.

C. B. Wang, W. X. Zhang. Environ. Sc. Tech. 31 (1997) 2154 -2156.

J. Waypa, M. Elimelech, J. Hering. J. Ame. Water Work Ass. 89 (1997) 102-114. 